\title{
Investigating of soil features and landslide risk in Western-Atakent (İstanbul) using resistivity, MASW, Microtremor and boreholes methods
}

https://doi.org/10.1515/geo-2019-0086

Received Jun 28, 2018; accepted Oct 28, 2019

\begin{abstract}
In Western-Atakent (İstanbul), population density is increasing day by day and settlement areas are expanding. Soil properties and landslide conditions of these expanding regions must be absolutely examined. In the geophysics, there are many methods used to investigate landslide risks and geotechnical structure. The most common geophysical methods used for this purpose are the Electrical resistivity tomography (ERT), Multi-channel Analysis of Surface Waves (MASW) and Microtremor Survey Method (MSM) methods. These methods are very successful techniques for defining underground layers as geological structures, stratigraphic elements, soil layer thickness and landslide. Because of that reason in this study, soil properties and possibility of landslides of the WesternAtakent (İstanbul) region were investigated by using ERT, MASW, MSM and drilling methods. In this study the first stage, electrical resistivity data have been measured using dipole-dipole method on two profiles for ERT. In the second stage, MASW measurements have been made at 25 points on 5 seismic profiles in the field. In the third stage, MSM measurements have been made to determine the fundamental period in the 5-measure station in the study area. In the fourth and final stage, 10-pieces boreholes with a depth of $20 \mathrm{~m}$ were drilled to reveal the lithological structure of the study area. As a result of the evaluation of all data, parts of the region that could form landslides were revealed.
\end{abstract}

Keywords: Landslide, ERT, MASW, MSM, boreholes, modelling

\footnotetext{
*Corresponding Author: Ayhan Keskinsezer: Sakarya University, Engineering Faculty, Department of Geophysical Engineering, 54050 Serdivan-Sakarya, Turkey; Email: ayhank@sakarya.edu.tr Ersin Dağ: Sakarya University, Engineering Faculty, Department of Geophysical Engineering, 54050 Serdivan-Sakarya, Turkey
}

\section{Introduction}

Landslides are a very common type of mass movement that occur frequently on the ground and play an important role in erosion. Large landslides leave deep traces in the topography at the same time. The landslide risk has been increasing in areas with high slopes. Generally, landslides occur in rainy or wet seasons. Water also facilitates landslide by reducing the angle of equilibrium, increasing weight and reducing friction. Also, landslides are very common in areas where clayey formations are common in deposits such as flysch, marl and tuff. There is a very close relationship between tectonic structure and landslide. Diving parallel to the slope of the strata facilitates landslides. Especially the presence of a clayey layer among the layers plays an important role. It is also known that earthquake waves trigger landslides. Thus, determining the risky areas for landslide is of great importance in estimating the landslide locations to be created by future earthquakes. Historical earthquake data shows that İstanbul is a risky city in terms of earthquakes. In the historical period, it is known that there are many earthquakes $\left(M_{S}>6\right)$ in İstanbul and its immediate surroundings.

Especially when topographical slope, earthquakes and landslides are considered, the study area between Küçükçekmece and Büyükçekmece Lakes on the western side of İstanbul (Figure 1) poses a risk for urbanization and population increase in the future.

This study covers the measurement, analysis and interpretation of the geophysical data in the study area in order to determine the soil properties and landslide risk of the Western-Atakent (İstanbul) region. The most suitable geophysical methods for the purpose of the study were determined and applied to the region and evaluated together with the well data.

ERT method has been used effectively in the search of underground resources such as soil structure, groundwater and mines. It is greatly used in determining the depth of ground water, determining the location of contaminated sites, and determining depth and reserve amounts in mine

๑ Open Access. (C) 2019 A. Keskinsezer and E. Dağ, published by De Gruyter 
fields. When the ERT method is supported by other geophysical methods and soundings, excellent results are obtained in determining the geological structure. For these reasons, various researchers [1-3] have successfully used the ERT method in different contexts of underground surveys. Broad evaluation of the reviews of the geophysical methods on landslide characteristic specifications can be found in [4] and [5]. In short, very high to very low resistivity values and very high to very low seismic velocity values characterize the body of a landslide in the region.

ERT measurements have been made on two profiles in order to model the resistivity changes of the study area. The dipole-dipole array technique was applied along multiple electrode profiles with the aid of a 60-electrode device to obtain detailed information during measurements.

Geophysical surveys such as MSM and MASW are very useful methods for delineating the subsurface stratigraphic structures, soil deposits, landslides and soils. Hence, geophysical prospecting has become a basic tool for the study of faults in a diversity of geological and tectonic sources $[6,7]$.

The method using multiple receivers, called as the MASW method permits successful identification of different seismic events from the dispersion curve of phase velocity versus frequency plot [8]. In this method also provides a 2D profile of the subsurface that was constructed by combining several 1D shear wave velocity profiles within the first $30 \mathrm{~m}$ [9]. Entire types of seismic waves, the surface waves have the strongest energy with the highest signal-tonoise ratio, making it a powerful tool for the near-surface characterization [10].

The information that MASW measurements will provide for the terrain is very important to understand the structure of the ground. Therefore, in the study area, 5piece profiles were formed to take the MASW measurements and 5 shots were made on each profile. Thus, in total 25-piece MASW data measured were taken. At later stage, MASW data has been evaluated and the ground structure was revealed.

One of the best favorite methods in recent years to determine soil properties is the horizontal-to-vertical spectral ratio (HVSR) method [11]. In this method is simply based on calculation of the ratio of horizontal to vertical MSM spectra to estimate the HVSR and predominant period for a single station. Many authors have successfully used this method on very different site response [11-15]. These authors in the studies have shown the correlation between the $\mathrm{H} / \mathrm{V}$ frequency peak and the fundamental resonance frequency of shear horizontal waves $[16,17]$. In this study, Nakamura [11] method has been applied as a reliable tool for estimating the fundamental period.
In addition, 10 boreholes were opened at various points in order to make correlation with geophysical methods and to obtain lithological sections. The results obtained from all these methods were evaluated together and the underground structure model of the study area was established.

\section{Geology and Tectonics of the study area}

The Marmara region between the Aegean Sea and Black Sea, is tectonically active region in northwest Turkey. This region is located on the North Anatolian Fault Zone (NAFZ) which is a great continental transform boundary between the Anatolian and Eurasian plates (Figure 1) [18, 19].

The Western-Atakent area located and totaling about $40.000 \mathrm{~m}^{2}$ in the western part of İstanbul in the Marmara region of Turkey (Figure 1). The surrounding area are highly active in terms of construction. Also, at the bottom unit is characterized by limestone of the Soğucak Formation and is Eocene age. This formation was deposited and formed under the control of topography and it is the result of a transgression together with sea level changes and morphology. Just above the Soğucak Formation is the Ceylan Formation with Upper Eocene age. This formation made up of limestone, calcareous sandstone, claystone, sandstone and tuff etc. sedimentary rocks. Just above the Ceylan Formation is the Gürpınar Formation with Oligocene age. The Gürpınar Formation belongs to the upper part of the Danişmen Formation. The Gürpınar Formation consists of clay, sand, gravel and calcareous sandstone. Just above the Gürpınar Formation is the Çukurçeşme Formation with Miocene age consists mainly of gravel or sand, clay and gravel. On over of the Çukurçeşme formation is the Güngören Member with Eocene age and consists of sandstone-shale intercalations. The Bakırköy Member consists of marls and limestones with latest Miocene age. The Alluvium is just above Bakırköy Formation. The Alluvium with Quaternary age in the study area is mainly composed of clay often contains the sand layers. There are widespread recent fillings on the Alluvium with Quaternary age. These fillings are remnants of a wide variety of sizes that cannot be clearly defined, such as material from foundation excavations, materials from demolished buildings, and old building remnants [20].

The elevation map of the study area and the drillings, seismic measurement profiles, resistivity profiles, MSM measurement points, topographic slopes and section lines (Figure 2) have been shown. 


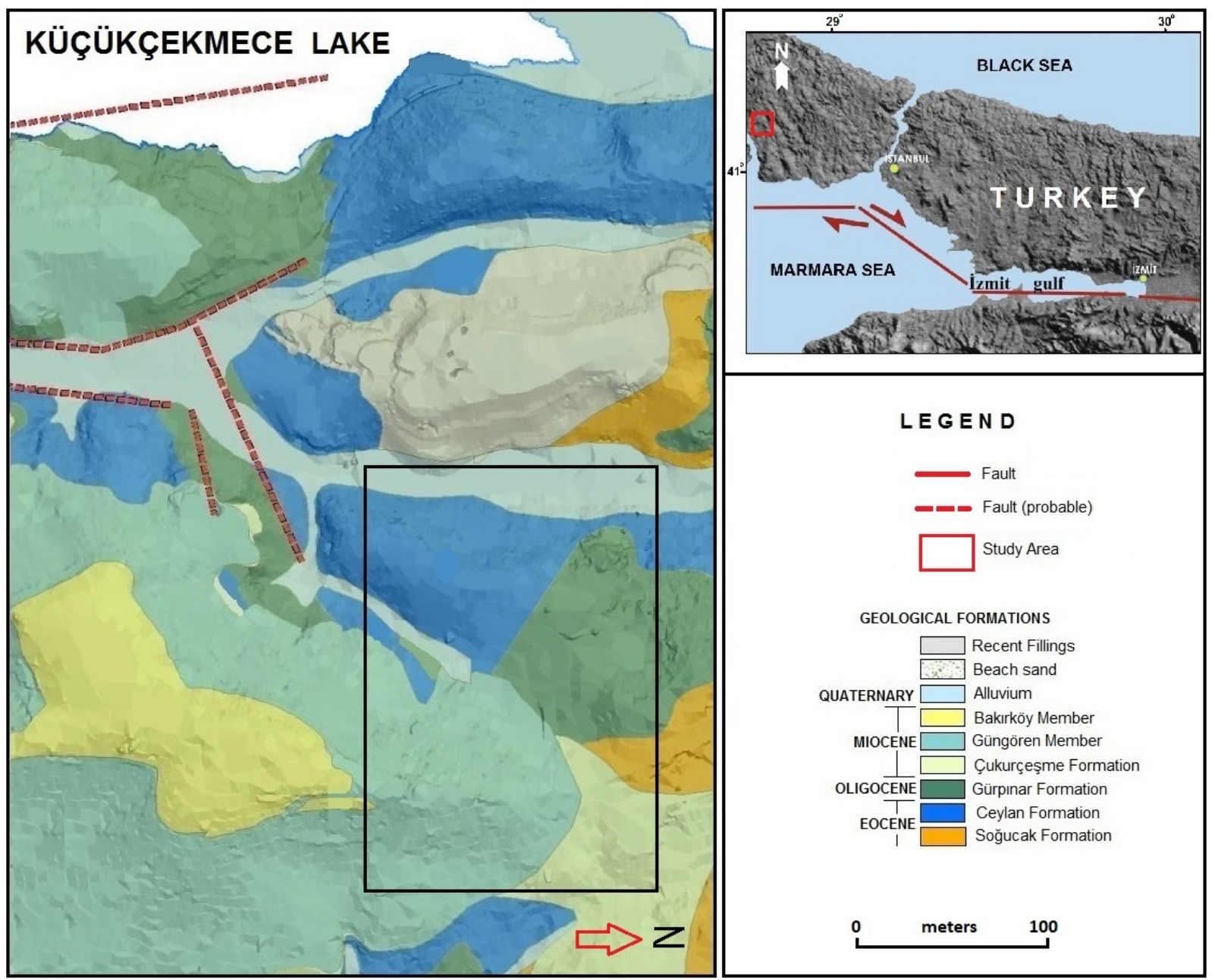

Figure 1: Geology map of the study area (modified from [38, 39]).

\section{Methods}

\subsection{Dipole-Dipole Multi-Electrode Array, ERT and Applications}

In the dipole-dipole system electrode array, the potential electrodes are placed outside of the current electrodes. Here, the distance between the current and the potential electrodes is opened at equal distances. In this system, the potential electrodes are very sensitive to lateral changes as they are outside the current electrodes. Unlike the Wenner and Schlumberger systems electrode arrays, the depth and location of measured values in the dipole-dipole system electrode array is the point of cut of two straight lines drawn at a 45-degree angle to the midpoint of current and potential electrodes. In this method, as the distance between the current and potential electrode pairs is opened, the resistivity values of depth levels such as $n=1, n=2, n$
$=3$ and etc. are measured respectively (Figure $3 \mathrm{a}$ and $3 \mathrm{~b}$ ). The dipole-dipole resistivity technique is the electrode array with the greatest penetration depth. It is also very sensitive to the determination of vertical discontinuities. This electrode array gives good results in the mapping of vertical structures such as dykes and voids (Figure 3c).

In recent years, improvements in electronics and computer technology have enabled the implementation of a multi-electrode resistivity measurement system, which can automatically change drilling-profile dimensions in one direction. The apparent resistivity values measured in this manner are calculated from the resistivity-depth values of the profile measured using inversion algorithms. With this measurement technique, information can be collected about the resistivity changes in both the horizontal and vertical directions. Since the multi-electrode system is developed in such a way that it can be taken in order of many measurements, it reduces the time required for measurement of the ground very much. Thanks to these practi- 


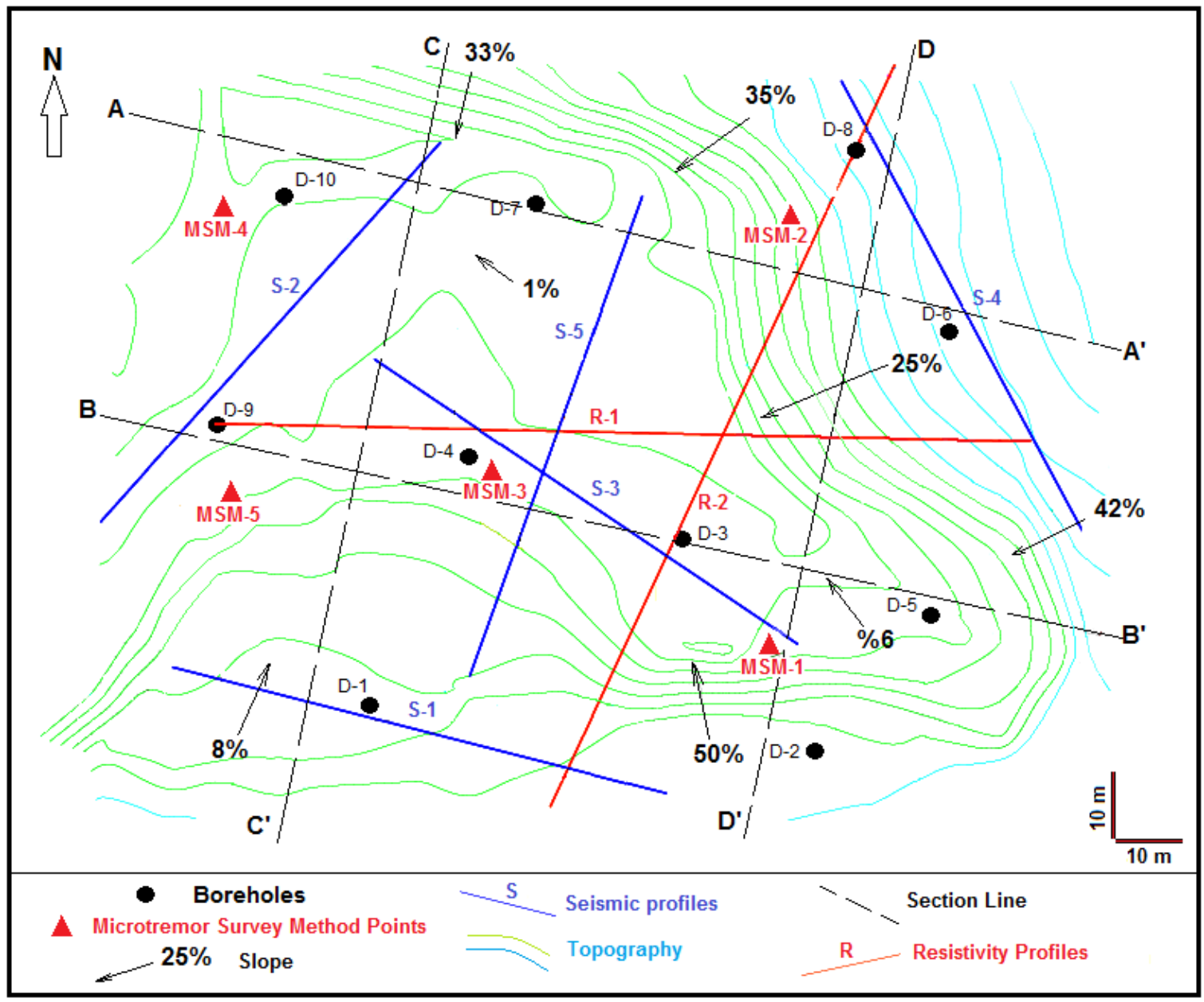

Figure 2: All geophysical measurement lines and technical data in study area.

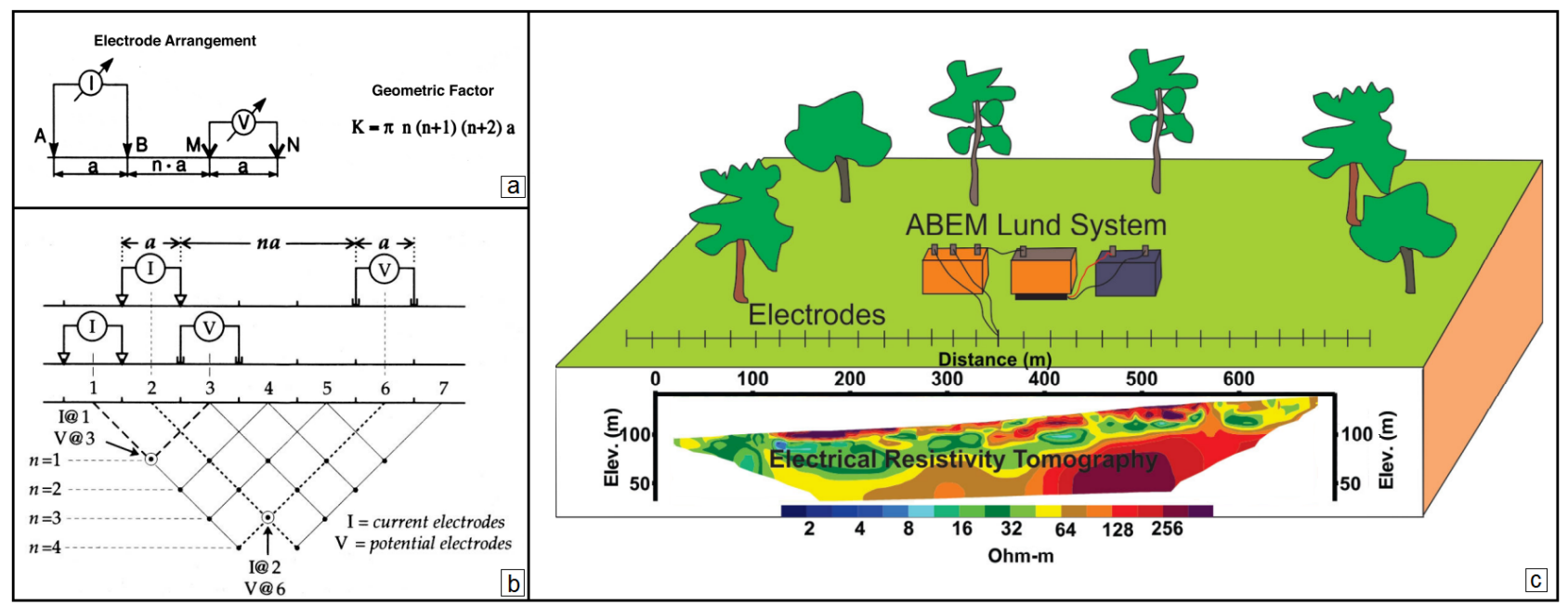

Figure 3: a) Dipole-Dipole electrode arrangements used in DC resistivity surveying and their geometric factor (modified from [40], b) Construction of a pseudosection for dipole-dipole resistivity data [41], c) Visual plan of multi electrode array showing the set-up and a possible ERT model obtained after inversion [42]. 


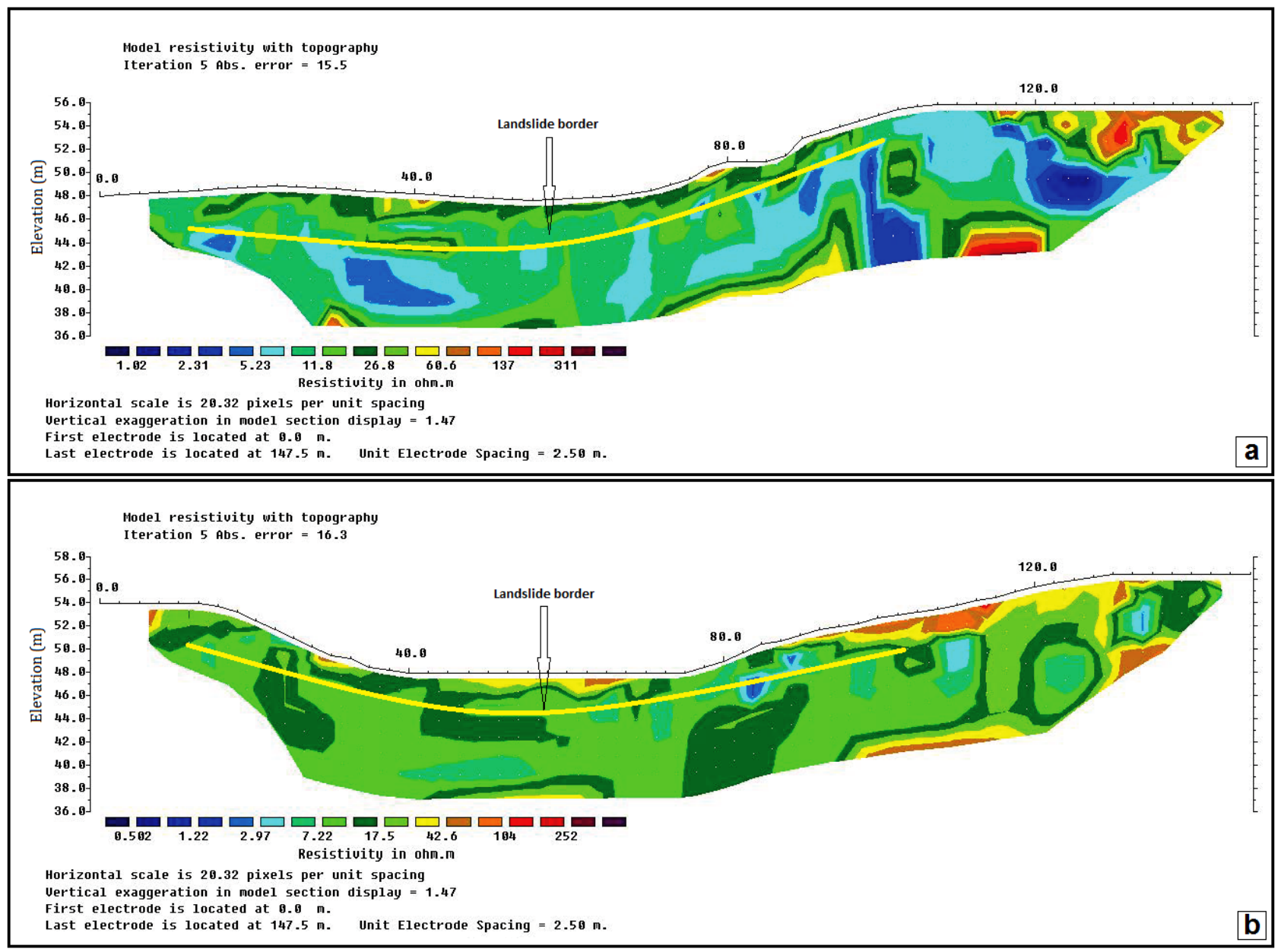

Figure 4: 2-D ERT with dipole-dipole array of profiles; a) Final section of R-1 profile and b) Final section of R-2 profile.

calities, this system presents 2-D and 3-D electrical resistivity tomography (ERT) imaging to reveal subsurface geological structures. Although many different electrode arrays can be used in the ERT method, choosing the most suitable array for the study increases the success of the result. ERT is one of the most used geophysical methods due to its solution powerful, cheaper than other methods, comfortable and present visual result of application and it is generally preferred in archaeogeophysics, groundwater exploration, landslide risk analysis and mining research etc.

In this study, resistivity measurements were taken on two profiles to model the electrical resistivity changes of the study area (Figure 2). A dipole-dipole array technique was applied along multiple electrode profiles with the aid of a 60-electrode device to obtain detailed information during measurements. ABEM SAS 1000 model resistivity meter and electrode separator ABEM Lund separator were used for the measurement [21]. As the electrode feature, $40 \mathrm{~cm}$ long and $12 \mathrm{~mm}$ diameter special copper alloy steel electrodes were used. For the operation of the device, 12 volt, 45 amperes dry type battery, $5.00 \mathrm{~m}$ electrode lead wire, each of which has 21 stations with $4 \times 100 \mathrm{~m}$ length cables are used. The electrode spacing was chosen as 2.5 $\mathrm{m}$ and measurements were made on 663 points on two lines with a length of $147.5 \mathrm{~m}$. The first of the resistivity lines is named R-1 and the second is named R-2. The apparent resistivity values obtained in the R-1 profile range from 0.84 to $862.52 \Omega \cdot \mathrm{m}$. In R-2 profile these values are between $0.40-764.25 \Omega \cdot \mathrm{m}$. The apparent resistivity data and the topographic level values of the electrodes were analyzed with RES2DINV [22] software and final sections were created (Figure 4). Resistivity values in the R-1 line have been found to be between 1.02 and $-311 \Omega \cdot \mathrm{m}$ and in the R2 line between 0.5 and $252 \Omega \cdot \mathrm{m}$. The iterative process has been continued until the 5th in order not to move away from the actual data in the inverse solution process.

Considering examine the final section of R-1 line, the area from the surface to the $20-30 \mathrm{~m}$ depth and between 10-30 $\Omega \cdot \mathrm{m}$ resistivity values shows a high filling material with dark green-light green colored clay ratio (Figure 4a). 


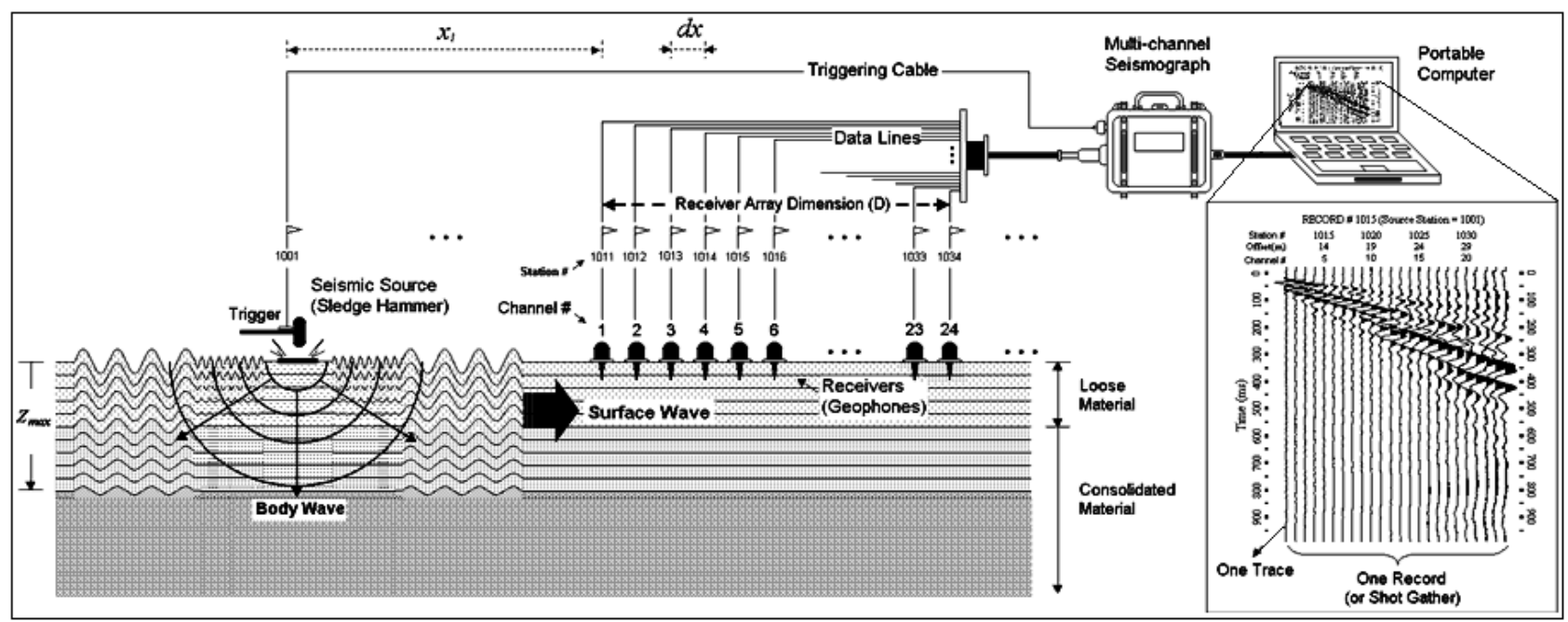

Figure 5: Typical multichannel seismic surface-wave experiment setup (modified from [23]).

The yellow-brown-orange regions appearing with high inclusions after about 110th meters of the horizontal axis gave high resistivity values due to the voided structure. The blue colored low resistivity region, which is also below the 120th metric in the horizontal axis, is the traces of water traced from hollow structure due to seasonal precipitation.

High-resistivity structures of yellow-brown-orangered color are observed in the horizontal axis at approximately 80 and 120 meters. These structures are thought to be limestones belonging to Upper Eocene-Lower/Middle Miocene Ceylan Formation. The middle region between these two units consists of claystones belonging to Gürp1nar Formation of Middle Oligocene-Early Miocene Danişmen Formation and Güngören Member of Upper Miocene Çekmece Formation.

In the final section of the R-2 line, the part from the surface to the dark green region is a filling material with a high clay content (Figure 4b). The filling properties of line R-2 are quite similar to those of line R-1. Although the limestone levels of the Ceylan Formation are not as pronounced, they can be distinguished by yellow-brownorange colors and also high resistivity values at the lowest levels between $40 \mathrm{~m}-80 \mathrm{~m}$ and $80 \mathrm{~m}-120 \mathrm{~m}$ in the horizontal axis. The area between these two units is the light greendark green color level in the section and it represents the claystones of Gürpınar Formation and Güngören Member.

When R-1 and R-2 cross-sections have been evaluated jointly, the resistivity values of the ground and filler levels are increased. The high clay content in the filler has been caused a difference in the resistivity values of this unit. The low resistivity values observed with small structures just below the surface are traces of water accumulation on the impermeable clayey layers.

\subsection{MASW Applications}

The technique to determine the shear wave velocities is applied using the surface waves. This is the most common type of MASW survey [23]. The maximum research depth that can be achieved is usually in the range of $20-30 \mathrm{~m}$, but this depth may vary with the strength of the active source and the structure of the lithology and soil types. MASW has been a surface wave analysis method in which various artificial and active sources such as sledgehammer or weight throwing have been used. The MASW method is based on the net dominance factor of the S-wave velocity, which propagates in the layered medium of the Rayleigh wave, from which the S-wave velocity profiles of the phase velocities are obtained. MASW data measurement system, seismic source, multiple geophones, multi-channel seismograph, portable computer and a record are shown Figure 5. In this method, the source and receivers have been arranged in the linear direction and multi-channel records have obtained.

The MASW data processing consists of three steps (Figure 6): the first step; preparation of land records for data processing phase (converting format), applying area geometry based on source and geophone locations. The second step is to obtain one dispersion curve for each record from the prepared data. Generating a good dispersion curve is important step, because the final result of a MASW survey depends on the frequency-phase velocity relation analyzed. 


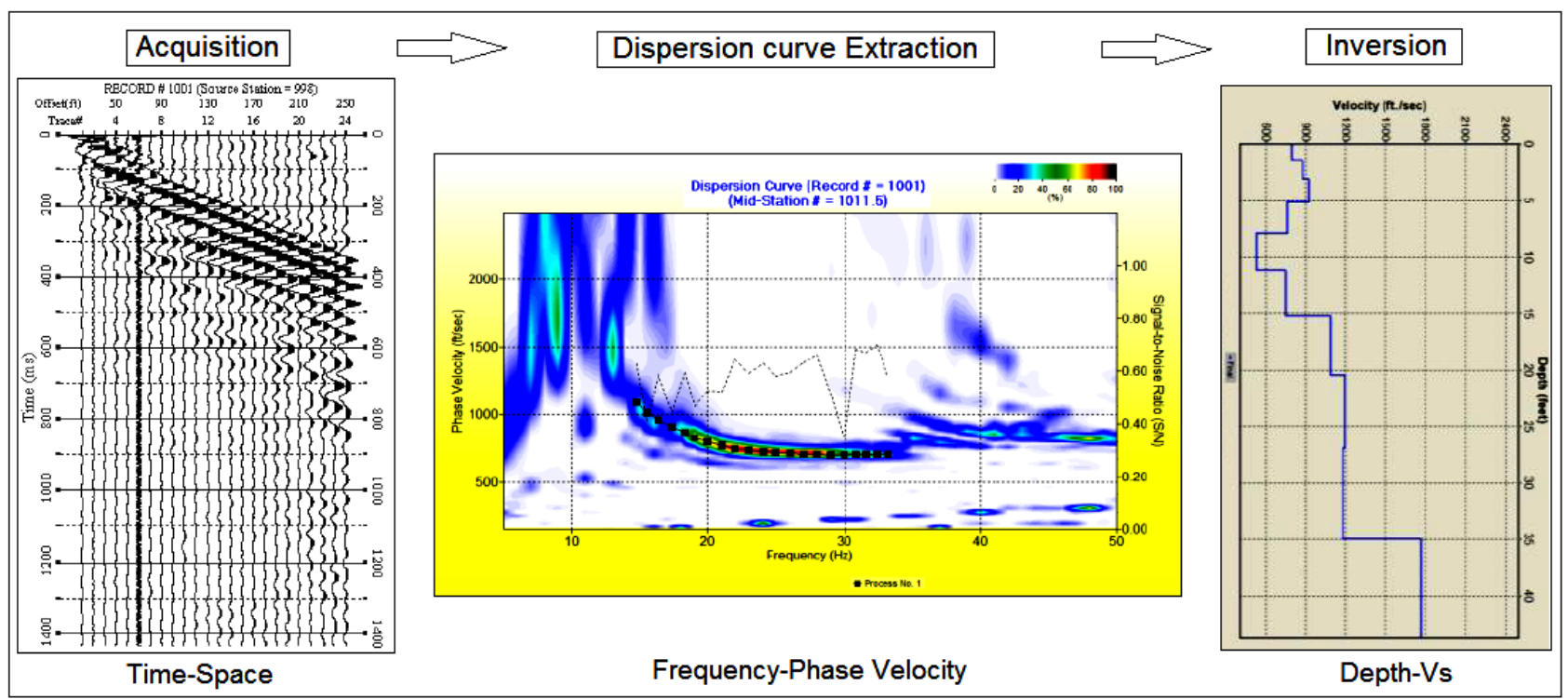

Figure 6: MASW data processing procedure (modified from [23]).

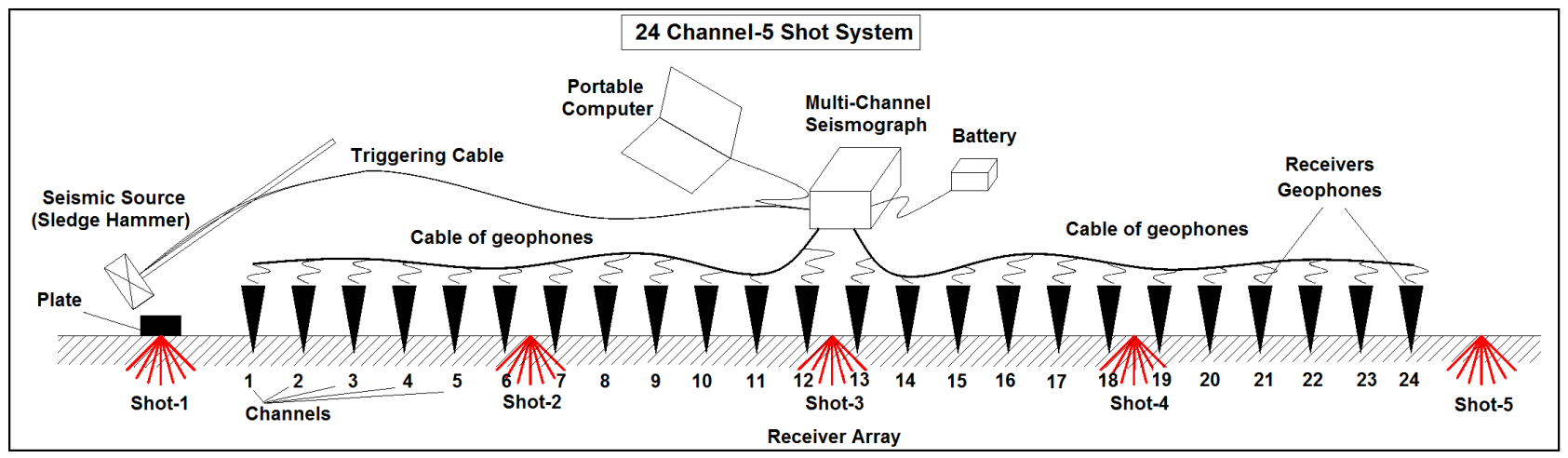

Figure 7: Measurement geometry of seismic lines.

This process is achieved by first converting the data from the time-space domain to frequency-phase velocity domain by using a suitable mathematical transformation process like the pi-omega transform [24] or the phaseshift method [8]. This type of 2-D (i.e., time and space) transformation generates image of dispersion patterns in both fundamental and higher modes through successive energy accumulations, instead of calculating individual phase velocities one by one. Among multiple modes of dispersion possibly recorded has been particularly interested in the fundamental mode dispersion curve, the one that is at the lowest velocity range. The last step of the MASW data processing involves inverting the surface wave dispersion data in order to obtain a 1-D seismic shear wave velocity profile. The inversion process involves backcalculating shear wave velocity variation with depth that yields the best fit between theoretical and measured dispersion curves [25].
In this study, MASW measurements have been made at 25 points on 5 seismic profiles in the field. Seismic measurement profiles have been shown in Figure 2. In this method, active energy source having been preferred and $10 \mathrm{~kg}$ sledgehammer having been used. In the survey measures, Seismic Source-DAQ Link-III model 24-channel engineering seismograph, the sampling interval is $0.25 \mathrm{~ms}$ and the recording length is 2 seconds, $3.00 \mathrm{~m}$ group distance and $3.00 \mathrm{~m}$ offset distance were used. In study 24 channels system, $69.00 \mathrm{~m}$ group and $72.00 \mathrm{~m}$ system distances have been selected. In addition to making straight and reverse shots from the offset distance of $3 \mathrm{~m}$ in the measure system, the shootings were also made among the geophones 6-7, 12-13 and 18-19 (Figure 7).

Dispersion curves were obtained using the PickWinSurface waves Analysis program (SeisImager). Dispersion curves express the change of the phase velocity depending on the frequency. This has helped me to calculate depths 

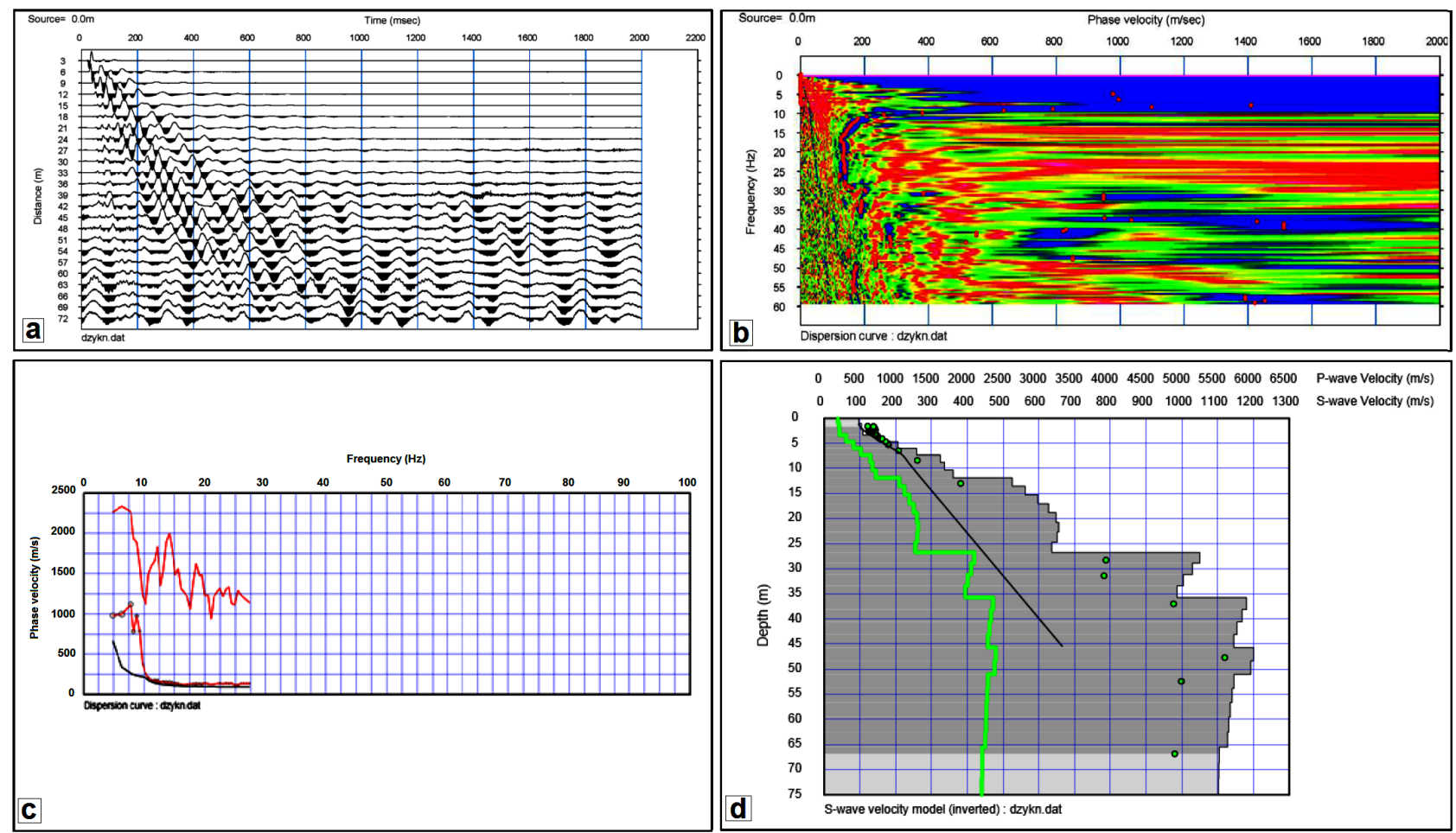

Figure 8: An example of the processed steps of MASW data (from S-1); a) Seismic record, b) Frequency-Phase velocity conversion, c) Iteration applied dispersion curve and d) Inverse solution result obtained depth-S wave velocity model.

in one dimension for every point. It is aimed to model the $\mathrm{S}$ wave velocities of seismic environments from the inversion of the dispersion curves obtained in the MASW method. For this purpose, inverse solution of dispersion curves was applied and S wave models were obtained (Figure 8).

The 1D S-wave velocity structure of each shot in each shot was combined with GPS and topographical values to create 2D depth-velocity sections (Figure 9).

The 3D image obtained from the MASW method of the study area is shown in Figure 10.

Seismic velocities near the surface are measured very low because the plates contain plenty of space and water. Below these levels, the presence of very solid-hard clay and claystone layers causes a noticeable increase in seismic speeds and makes a difference from the strata above. The limestones at the bottom are striking at very high seismic velocities due to their geological characteristics.

As a result, that, the high frequency parts of the MASW dispersion curves, whichever correspond to shallow depths $<5 \mathrm{~m}$, while the low frequency parts of the dispersion curves, so that correspond to areas deeper than average $25 \mathrm{~m}$. When all seismic velocity profiles are investigated, it is seen that the result is the $S$ wave velocity is less than $200 \mathrm{~m} / \mathrm{s}$ near the surface. At the bottom, limestone levels imply that the $S$ wave velocity is at very high speeds such as $850-1000 \mathrm{~m} / \mathrm{s}$. Among these two distinct seismic environments, there is another layer which is observed at 500-800 m/s (Figure 9 and Figure 10).

As a result, clay with low seismic velocities at the top, silty-sandy-gravel clay and marls with moderate seismic velocities immediately below, and limestones with high seismic velocities at the bottom can be interpreted. The differences observed at seismic velocities in the marl and limestone levels are thought to be due to the effect of the potential groundwater on the areas that do not show uniform propagation.

\subsection{MSM Applications}

According to Nogoshi and Igarashi [26], involves recording a few minutes of seismic background noise to provide a reliable estimate of the soil resonance frequency, in here based on the essentially Rayleigh-wave nature of the MSM used. The researchers compute the spectral ratio of the horizontal and the vertical components of an MSM measurement for a single station. The resulting curves pinpoint a frequency that is supposed to fit remarkably with the Swave resonance frequency of the studied site. This technique was later revised by [11], who claimed more largely that this HVSR is a reliable assessment of the site trans- 


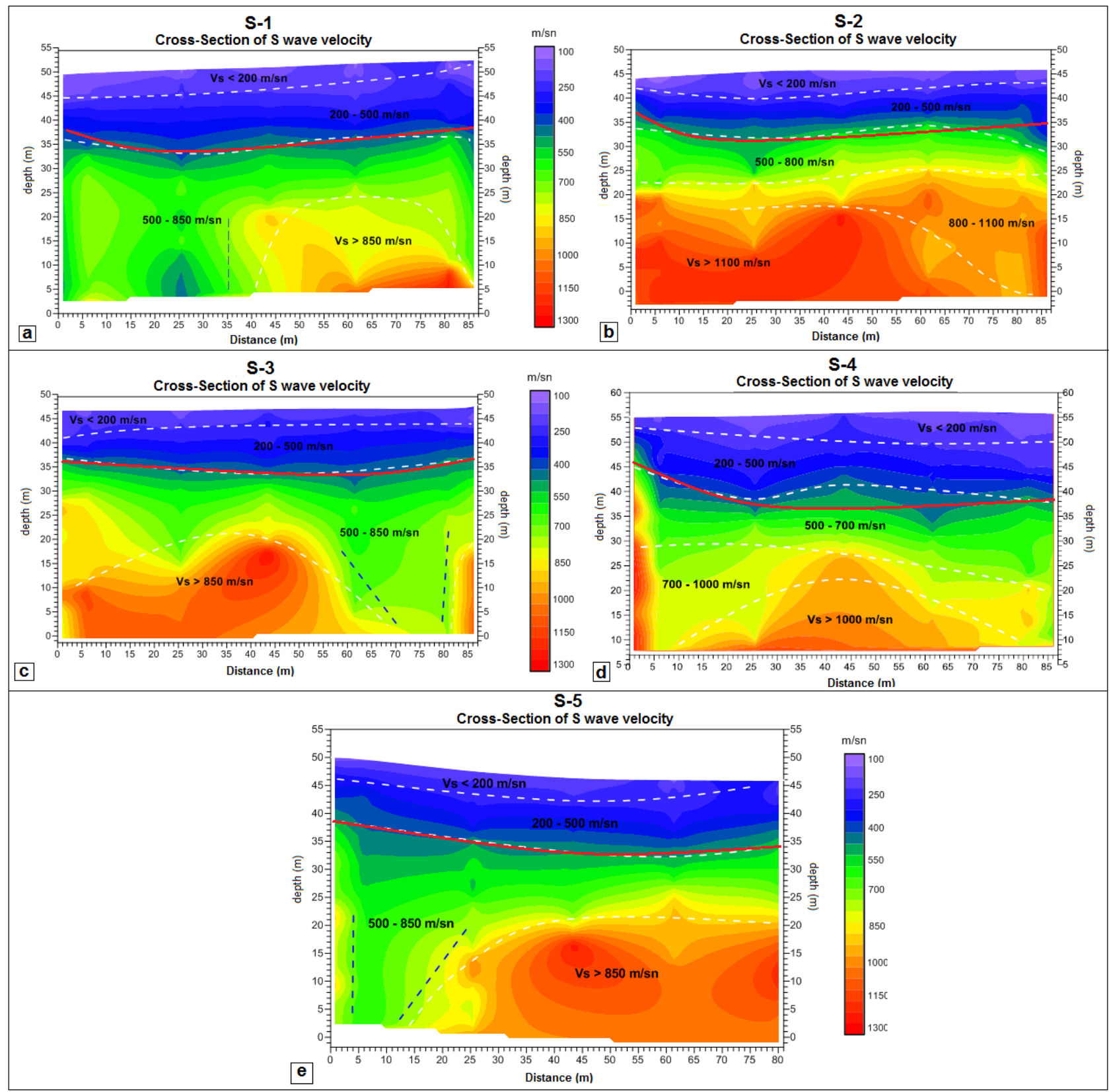

Figure 9: Depth-S wave velocity sections of the seismic profiles; a) S-1 line, b) S-2 line, c) S-3 line, d) S-4 line and e) S-5 line.

fer function for S-waves with respect to bedrock, because of the mainly body wave nature of the noise. In many research carried out over the recent years, showed that this $\mathrm{H} / \mathrm{V}$ ratio on MSM is much more stable than the raw noise spectra, and that in case of high impedance contrast between surface and deep materials, the MSM exhibit a clear peak which is well correlated with the fundamental resonance frequency $[12,27,28]$. The recent numerical simulations of background noise $[12,17,29,30]$ confirmed Nogoshi and Igarashi's [26] first explanations as concerns the surface-wave nature of MSM: synthetic calculations showed the direct link between three values in case of a single soft surface layer over bedrock: the ellipticity curves of Rayleigh waves, the frequency pinpointed by the HVSR on MSM and the S-wave resonance frequency of soft soil under the studied site. But these results also predicted no correlation between the amplitude of this $\mathrm{H} / \mathrm{V}$ peak and the actual amplification value under S-wave incidence (except for [29]). Yet, several authors claim a satisfactory empirical agreement between the level of the two types of curve [31, 32]. Recent investigations concerning this tech- 


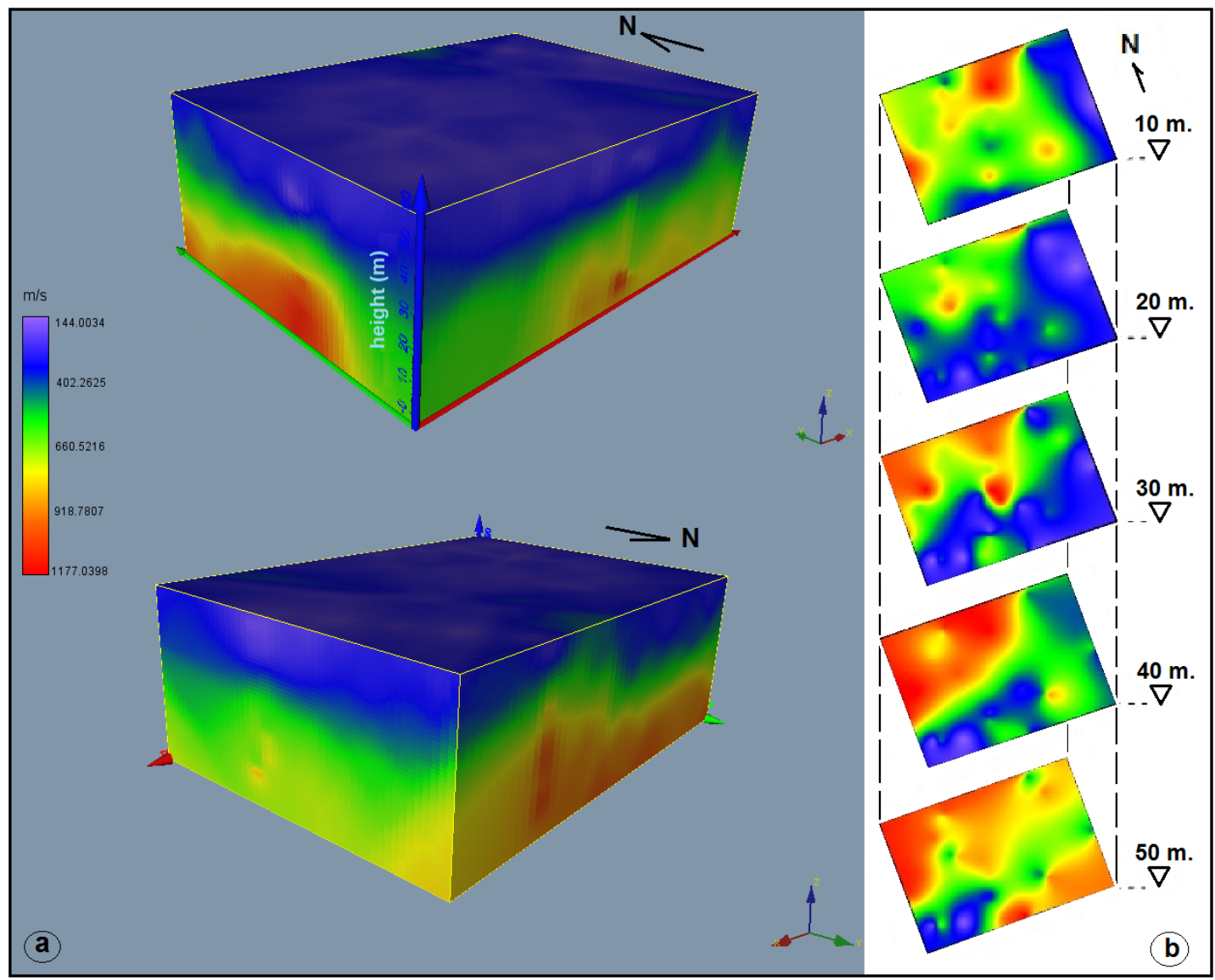

Figure 10: a) 3-D image obtained from MASW method of the study area, b) Level maps with $10 \mathrm{~m}$ intervals.

nique are reviewed in [33-36]. The computation of the HVSR follows different steps is shown Figure 11.

MSM measurements have been made to determine the fundamental period for the study area and its immediate surroundings. In particular, 5-pieces measuring points are selected in locations that allow us to measure all the characteristics of the study area (Figure 2). Measurements in the area were taken using $\mathrm{PE}-6 / \mathrm{B}, 3-$ component geophone. This geophone contains the SM-6/U-B $4.5 \mathrm{~Hz}$ vertical geophone and two SM-6/H-B $4.5 \mathrm{~Hz}$ horizontal geophones. Seismic Source-DAQ Link III model 24-channel engineering seismograph was used as data collector. MSM records were primarily filtered with a bandpass filter at 0.1$20 \mathrm{~Hz}$ for environmental noise. Fourier spectra were calculated using window length of 100 seconds after the filtering process was completed. During the calculation of the Fourier spectra, the value of $b$ was applied to the measured values by assuming a value of 40 for the rounding. The MSM records of the MSM points in the area and the selected windows on the records are shown in Figure 12. HVSR in solution phase and MSM results of the measured data is using solved the GEOPSY software [37], which works with the Nakamura method [11].

The results obtained and the number and length of windows used for evaluation are shown in Table 1. As a result of interpretation of $\mathrm{H} / \mathrm{V}$ curves; it is seen that the same frequency values are obtained at the MSM- 1 and MSM-3 points. When the H/V curves at MSM- 4 and MSM-5 points are examined, a single frequency peak is observed. Considering at the $\mathrm{H} / \mathrm{V}$ curves obtained from other stations, it is seen that the peaks do not collect a Single frequency and give peaks at different frequencies. As a result, soil Layer thickness was calculated for each station using MSM data (Figure 12). Soil layer thickness of about 9-24 $\mathrm{m}$ was found in the area (Table 1). The measurement points of MSM-1, MSM-3 and MSM-5 are located on the line of B-B' geological section with S-3 MASW section. Period values of these 3 points in the range of $0.24 \mathrm{sec}$ to $0.27 \mathrm{sec}$ indicate the landslide area along this profile. MSM-2 and MSM-4 points are consistent with the geological section A-A'. When the A-A' geological section was examined, the period values of these points were low $(0.13 \mathrm{sec}-0.19 \mathrm{sec})$ due to the upward intrusion of limestone (Ceylan Formation). 
Table 1: MSM evaluation results

\begin{tabular}{ccccc}
\hline $\begin{array}{c}\text { Station } \\
\text { Number }\end{array}$ & $\begin{array}{c}\text { Number of } \\
\text { windows }\end{array}$ & $\begin{array}{c}\text { Predominant Ground } \\
\text { Period } \mathrm{f}_{0}(\mathrm{~Hz})\end{array}$ & $\begin{array}{c}\text { Ground Vibration Period } \\
\mathrm{T}_{0}(\mathrm{sn})\end{array}$ & $\begin{array}{c}\text { Soil Layer Thickness H } \\
(\mathrm{m})\end{array}$ \\
\hline MSM-1 & 17 & 4,01 & 0,24 & 20.50 \\
MSM-2 & 20 & 7,23 & 0,13 & 9.22 \\
MSM-3 & 16 & 4,01 & 0,24 & 20.50 \\
MSM-4 & 14 & 5,24 & 0,19 & 14.29 \\
MSM-5 & 22 & 5,60 & 0,27 & 23.82 \\
\hline
\end{tabular}

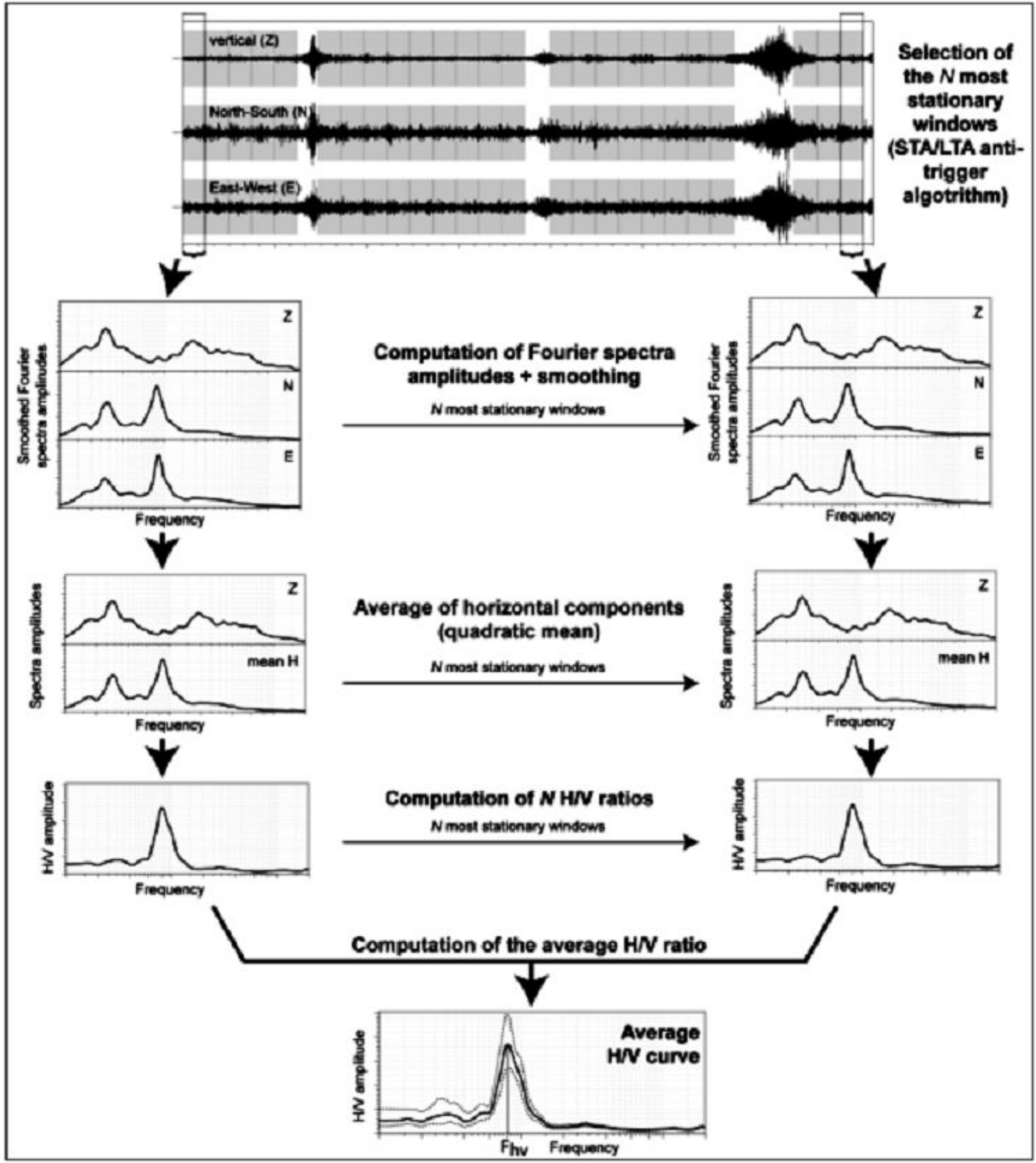

Figure 11: Description of the computation of HVSR [37]. 

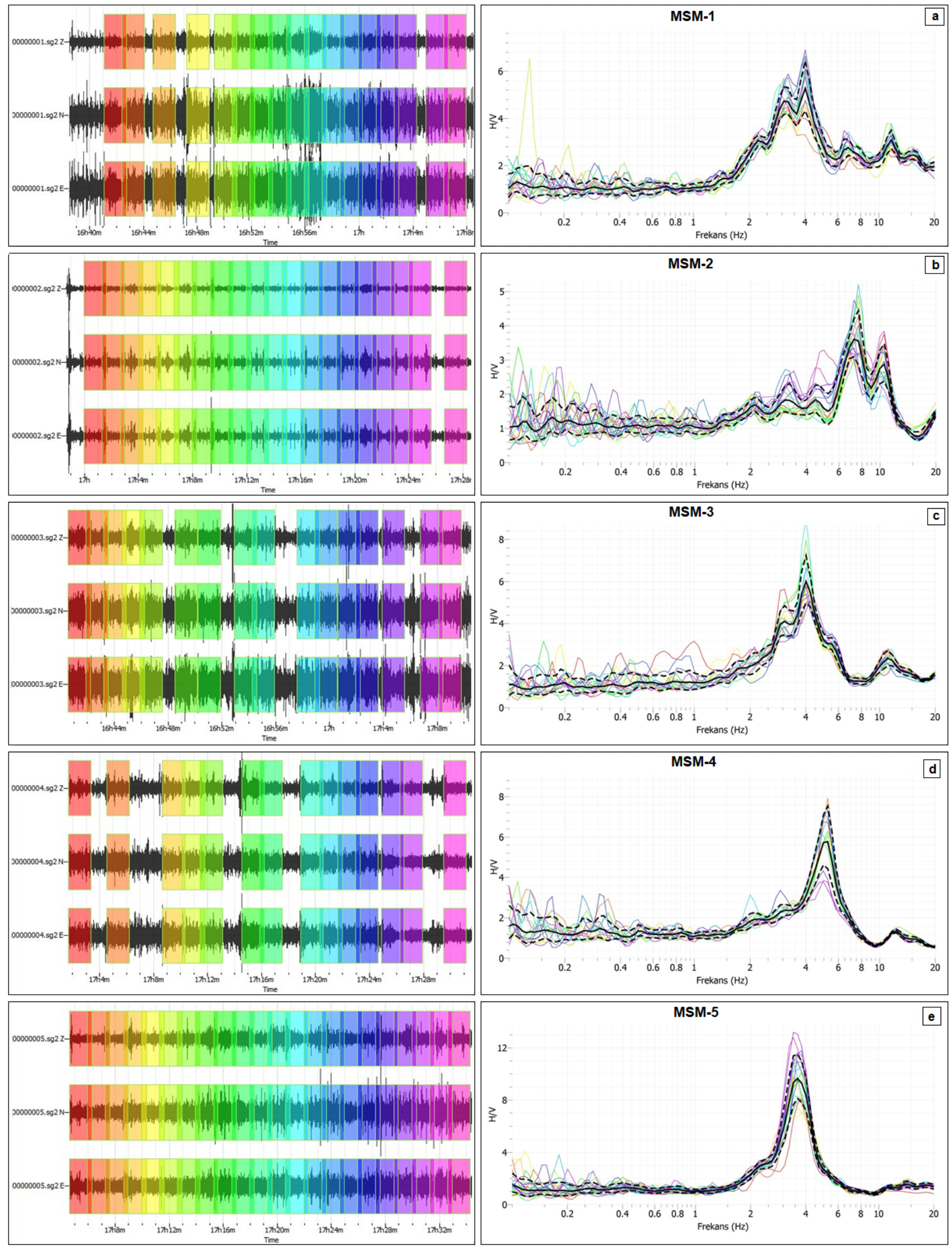

Figure 12: MSM records of MSM stations and selected windows; a) MSM-1, b) MSM-2, c) MSM-3, d) MSM-4 and e) MSM-5. 


\subsection{Drillings and Lithological Sections}

In this study, ERT, 3D MASW, MSM and boreholes methods have been applied in order to investigate the engineering base rock topography, underground layer models, landslides and faults of the land located in Western-Atakent (İstanbul). In order to determine the lithological structure of the study area and to obtain sections, 10 wells with a depth of $20 \mathrm{~m}$ have been drilled. Using all the results obtained, 4 lithological sections have been created in the directions shown in Figure 2.

From the lithological sections A-A', B-B', C-C' and D-D' obtained respectively; Starting from the surface, silt-gravel within the range of 7-7.5 m is generally more clay, artificial filling material has been observed. Widespread fillings in the region have been intertwined with natural grounds due to the long-term effect and irregular structure. The environment in which A-A' section is taken is inclined from the topographical aspect. When the A-A' section is examined from the surface to the deep, the first $8 \mathrm{~m}$ alluviums are followed by the 2-8 $\mathrm{m}$ Çekmece Formation and the lowest layer is followed by Ceylan Formation. Here the sedimentary layer is very thick and the Çekmece Formation is a very thin layer. The Ceylan Formation, which was observed to be very thick in the drills of D-7 and D-10, could not be observed in drilling of D-6. Only the alluvial layer and the Çekmece Formation were observed in the drilling D-6 (Figure 13a).

It is understood that Çekmece and Danişmen formations are found as the second layer in D-9 sounding also Ceylan formation layer are found in D-4, D-3 and D-5 soundings. In the drilling of D-9, Çekmece Formation is located as the second layer, while in the drillings of D-4, D-3 and D-5, Danişmen Formation layer is located. In all the boreholes in this section, the lowest layer is Ceylan Formation (Figure 13b). In the C-C' section, the drilling of D-7 passes through the alluvial stratum, then Çekmece Formation and then Ceylan Formation. In the drilling of the D-7, Çekmece Formation is a very thin layer. Alluvium, Danişmen Formation and Ceylan Formations were observed in D-4 drilling, respectively. The layers under this alluvium are curved. In the drilling of D-1, 10m thick alluvium, 3m thick Çekmece Formation and then Danişmen Formation layers were passed (Figure 13c). In drilling D-8 located at section D-D', alluvium is $6 \mathrm{~m}$ thick, Çekmece Formation is $1 \mathrm{~m}$ thick and Ceylan Formation is $12 \mathrm{~m}$ thick. In drilling D-5, there are alluvium of $9 \mathrm{~m}$, Danişmen Formation of $4 \mathrm{~m}$ and Ceylan Formation of $7 \mathrm{~m}$. almost the same values are observed in the drilling D-2 (Figure 13d).

\section{Results}

Only sounding information is not enough for the expression of the underground complex structure. At the same time, methods that produce solutions in one dimension do not fully reflect underground structure. By using 2D and 3D geophysical methods, measuring the physical properties of the underground structure and correlating it with the drilling information, the nearest real situation can be revealed. For this reason, three separate geophysical methods have been applied to the area and correlated with the above drilling data.

In order to determine the resistivity changes of the study area, two-line $147.5 \mathrm{~m}$ long multiple electrodes have been applied. It has been understood that the resistivity values of the ground are in the range of approximately 0.76 $281.5 \Omega \cdot \mathrm{m}$. Thus, results from the two resistivity profiles is shown possible landslide surfaces at a depth of range 20$30 \mathrm{~m}$. This landslide structure marked with red lines and arrows in Figure 4a,b. According to this information, the impermeable claystone's of the Danişmen Formation and the clay levels of the Çekmece Formation are clearly identified, while the limestones of the Ceylan Formation are slightly seen. The electrical resistivity values are very low as expected due to water and claystone's ingredient. For the expected structure of the landslide, the geological observations also revealed the results supported the geophysical research.

Seismic measurements were made at 25 points in 5 different directions profiles created in the study field and it was aimed to determine the speed structures of the seismic basement and the layers over it. MASW was applied to the measurements and $S$ wave velocity models were created. The 1D models belonging to Profiles were combined and 2D speed sections were created. The velocity sections were separated into seismic media and the $\mathrm{S}$ wave velocities of the fill levels were found to be lower than $200 \mathrm{~m} / \mathrm{s}$. The $S$ wave velocities of the limestone levels of the Ceylan Formation range from $850-1000 \mathrm{~m} / \mathrm{s}$. between these two seismic environments, 2 seismic environments are seen in some sections and 1 in some sections. These are clays of Çekmece Formations with $\mathrm{S}$ wave velocities ranging between $200-500$ m/s and claystone's of Danişmen Formation with $S$ wave velocities ranging between $500-800 \mathrm{~m} / \mathrm{s}$. The traces of existing stream on the topography of the 3rd and 5th Profiles were also observed and marked in seismic studies. Later on, 2D velocity sections have been combined and 3D velocity images have been obtained. Starting from the surface, a floor map at $10 \mathrm{~m}$ was also created and a detailed examination of the seismic base and speed structure 

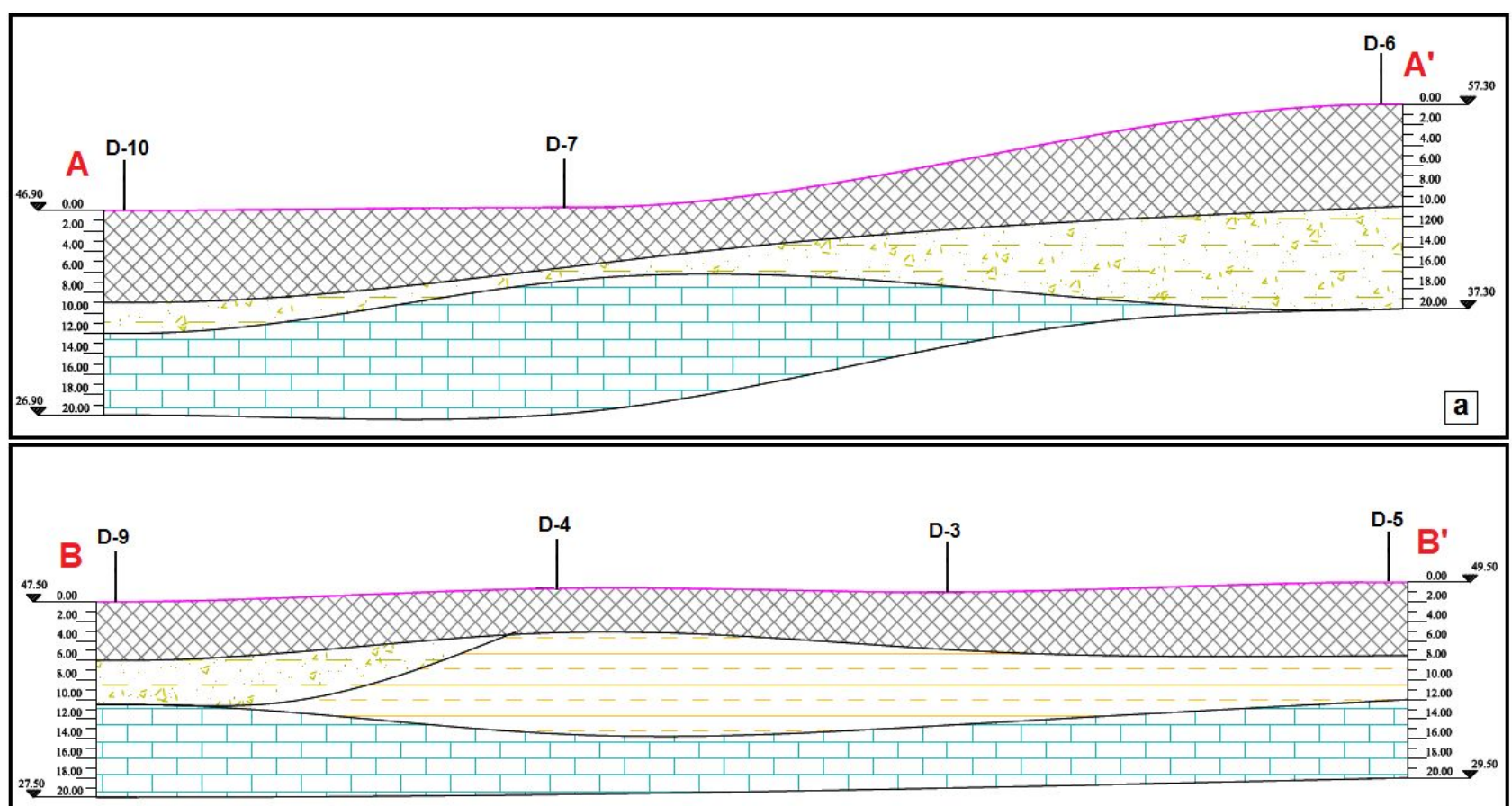

b
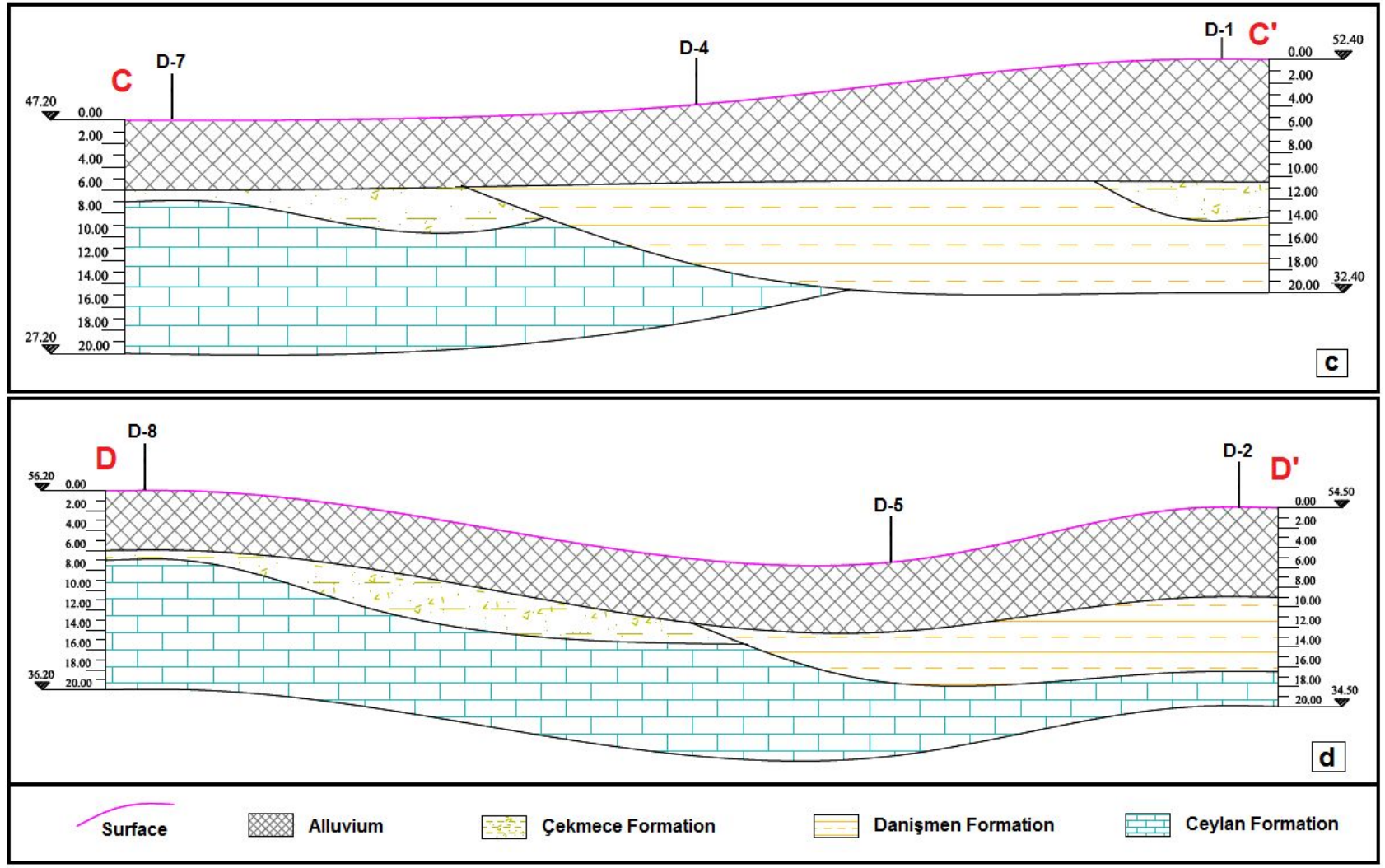

Figure 13: Lithological section lines used in the study area; a) A-A', b) B-B', c) C-C' and d) D-D'. 


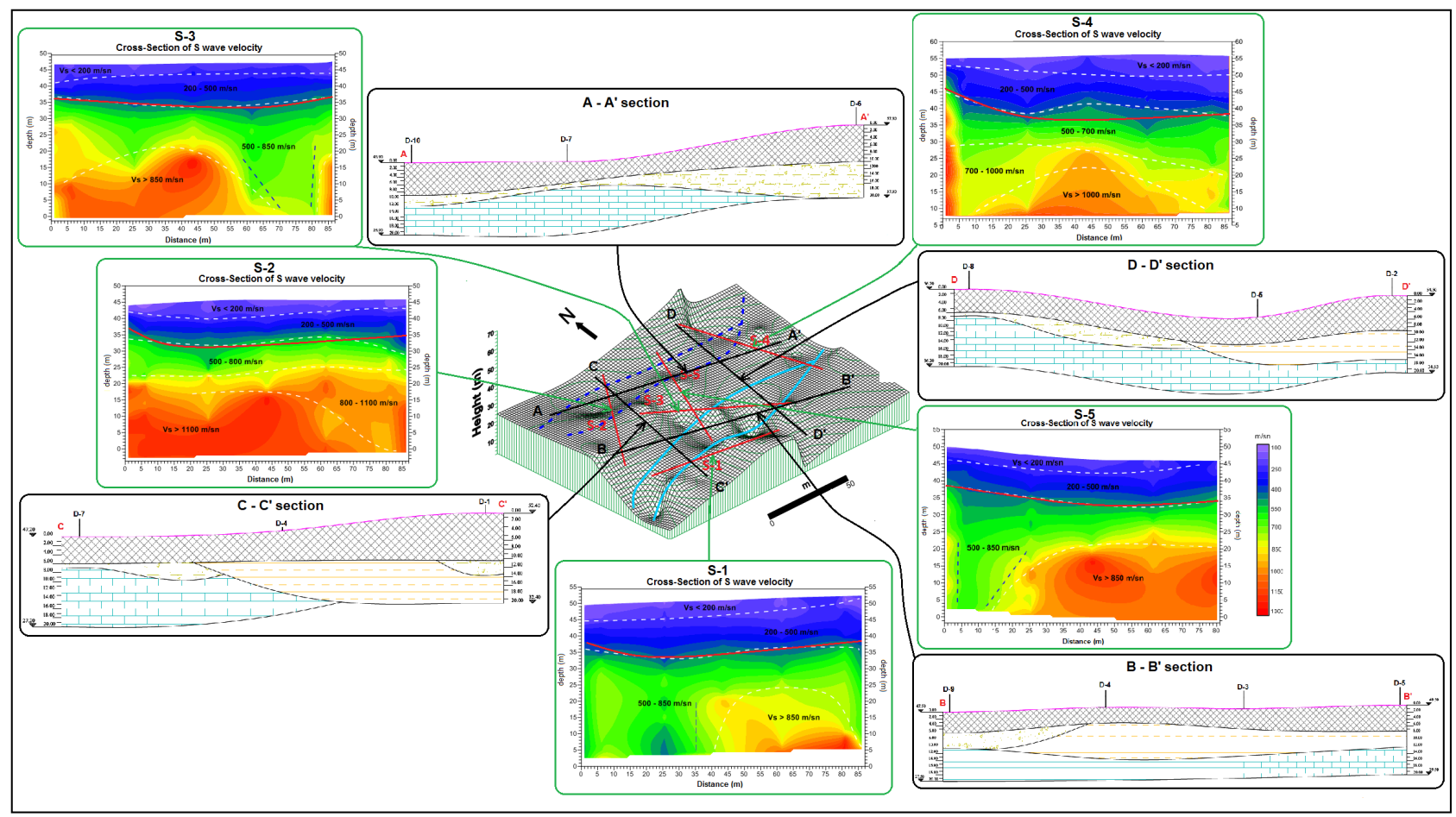

Figure 14: Evaluation and correlation of MASW images and geological borehole sections of the study area.

of the land was made. Accordingly, it is seen that seismic velocities increase on the NW side of the land, especially after 30 m levels (Figure 10). That, it is difficult to identify any slip surface, however the high-velocity contrast and the asset of water can be mark local slides at shallow depths.

The images of S-wave velocity shown in Figure 9 provide with some trace related to the structure of the landslide. The S-wave velocities are very low, approximately < $200 \mathrm{~m} / \mathrm{s}$ into the upper layer, and they increment up to 800 $1000 \mathrm{~m} / \mathrm{s}$ at the depth among 35-40 m. Attention that the $\mathrm{S}$-wave velocities are usually lower within the boundary of the landslide with respect to the surrounding area. The cross sections of S-wave velocities shown in Figure 9 could be more useful to use to interpretation the landslide geometry. The layers with the $S$-wave velocity lower than $<200$ $500 \mathrm{~m} / \mathrm{s}$ the thicknesses of those layers are approximately $20-25 \mathrm{~m}$. The layers with velocities of average $>500-800$ $\mathrm{m} / \mathrm{s}$ or higher extend from the bottom of the moving layer to the edges of the landslide area are aforethought as stationary parts. On the other hand, particularly as is seen S-2 and $\mathrm{S}-5 \mathrm{~S}$ wave velocity cross sections in areas deeper than 20-25 m, the $S$ wave velocities begin to be the same for the all area. For this reason, this level can be evaluated as the bottom boundary of the landslide body.

Predominant Ground Period $\left(\mathrm{f}_{0}\right)$ values are varies between 4.01-7.23 Hz. and Ground Vibration Period $\left(\mathrm{T}_{0}\right)$ values between $0.13-0.27 \mathrm{~s}$ in MSM measurements. As a conse- quence of the MSM measurements, in the northern part of the soil thicknesses are relatively low (approx. 9-14 m) and the soil thickness increases considerably in the SE direction (approx. $24 \mathrm{~m}$ ). As shown in Table 1, in the middle part of the study area, the resonance frequencies are observed between $4.01 \mathrm{~Hz}$, however at the sites in the outside area, the values increase to 5.24-7.23 $\mathrm{Hz}$. This differentiation of resonance frequencies in the study area is thought to be the result of the landslide mass generating a specific vibration resonance distinct from the true soil resonance. Because the thickness of the soil in the high frequency (5.24$7.23 \mathrm{~Hz}$ ) region is between $20.5-23.82 \mathrm{~m}$. The measurement points of MSM-1, MSM-3 and MSM-5 are located on the line of B-B' geological section with S-3 MASW section. Period values of these 3 points in the range of $0.24 \mathrm{sec}$ to $0.27 \mathrm{sec}$ indicate the landslide area along this profile. MSM-2 and MSM-4 points are consistent with the geological section AA'. When the A-A' geological section was examined, the period values of these points were low $(0.13 \mathrm{sec}-0.19 \mathrm{sec})$ due to the upward intrusion of limestone (Ceylan Formation).

The results obtained from ERT, MASW, MSM and Lithological section methods applied in the study have been evaluated and correlated with each other. The results obtained by geophysical methods were interpreted together with the results obtained from geological data. The evaluations made show that the results of the applied methods are in harmony. As a result, a 3D model was obtained in 
which the depth of the engineered bedrock of the study area and traces of the old creek beds (cut-dark blue line and light blue line) were also observed (Figure 14). As shown in Figure 13, the basic slip surface of the Atakent landslide improves in the same geological unit occur of the clayey layers of the Ceylan Formation. For this reason, it does not constitute a strong impedance contrast among the landslide body and underlying layers. In addition, in the study area, there are soil and sediments such as excavation materials extracted from the nearby construction foundations, which were brought to the region and irregular poured and mixed into the layers.

The topographic slope in the study area and its vicinity is highly variable as seen in Figure 2 . These slopes were formed after fillings and are $25-50 \%$ in slopes and $1-6 \%$ in creek beds. These slope quantities are such that when mass movements are taken into consideration, they can create problems with the effect of groundwater. According to environmental observations made in the study area, the slits in the southern and northern parts are very striking (Figure 2). This case is clearly observed in Figure 9a, b, c where the $S$ wave velocity obtained from the seismic MASW method is located in the land crossings.

\section{Discussions}

The regions delimited by the cut lines on the MASW sections and defined by the velocity of $500-850 \mathrm{~m} / \mathrm{s}$ Vs are projected to be related to these slits. Water entry from these slits is possible due to seasonal rainfall. Therefore, in order to remove the stability problem from the middle of the stability problem and the cross-sections obtained after the multielectrode measurements, the gravel-clay geometry under the filler may form a shear zone, the load balance relation of the excavations to be done needs to be established. Probably, of the building excavations need to be done in a controlled manner by taking these risks into account and it is suggested to remove the fillings levels. Otherwise, the presence of mass movements will be inevitable.

\section{References}

[1] Caris, J.P.T., Van Asch, Th.W.J., Geophysical, geotechnical and hydrological investigations of a small landslide in the French Alps. Eng. Geol., 1991, 31, 249-276

[2] Lapenna, V., Lorenzo, P., Perrone, A., Piscitelli, S., Rizzo, E., Sdao, F., 2D electrical resistivity imaging of some complex landslides in Lucanian Apennine chain, southern Italy. Geophysics, 2005, 70, B11-B18

[3] Meric, O., Garambois, S., Malet, J.-P., Cadet, H., Gueguen, P., Jongsman, D., Seismic noise-based methods for soft-rock landslide characterization. Bull. Soc. Geol. Fr., 2007, 178 (2), 137-148

[4] Hack, R., Geophysics for slope stability. Surv. Geophys. 2000, 21, 423-448

[5] Jongmans, D., Garambois, S., Geophysical investigation of landslides: a review. Bull. Soc. Geol. Fr., 2007, 178 (2), 101-112

[6] Peters, G., Buchmann, T. J., Connolly, P., van Balen, R. T., Wenzel, F., \& Cloetingh, S. A. P. L., Interplay between tectonic, fluvial and erosional processes along the Western Border Fault of the Northern Upper Rhine Graben, Germany. Tectonophysics, 2005, 406, 39-66

[7] Vanneste, K., Verbeeck, K., Petermans, T., Pseudo-3D imaging of a low-slip-rate, active normal fault using shallow geophysical methods: the Geleen fault in the Belgian Maas River valley. Geophysics, 2008, 73(1), pp. B1-B9

[8] Park, C.B., Miller, R.D., Xia, J., Imaging dispersion curves of surface waves on multi-channel record. The Society of Exploration Geophysicists, Expanded Abstracts, 1998, 1377-1380

[9] Xia, J., Miller, R.D., Park, C.B., Hunter, J.A., Harris, J.B. and Ivanov, J., Comparing shear-wave velocity profiles inverted from multichannel surface wave with borehole measurements. Soil Dynamics and Earthquake Engineering, 2002, 22, 3, 181-190

[10] Park, C.B., Miller, R.D. and Miura, H., Optimum field parameters of an MASW survey. [Exp. Abs.]. SEG-J, Tokyo, 2002, 22-23

[11] Nakamura, Y., A method for dynamic characteristics estimations of subsurface using microtremors on the ground surface. Quart. Rep. Railway Tech. Res. Inst. (RTRI), 1989, 30, 25-33

[12] Field, E. and Jacob, K., The theoretical response of sedimentary layers to ambient seismic noise. Geophys. Res. Lett. 1993, 20, 2925-2928

[13] Lermo, J. and Chávez-García, F. J., Are Ambient noise Useful in Site Response Evaluation? Bull. Seismol.Soc. Am., 1994, 84, 1350-1364

[14] Jensen, V.H., Seismic microzonation in Australia. Jour. Asian Earth. Sci., 2000, Vol 18, pp 3-15

[15] Chávez-García, F.J. and Tejeda-Jácome, J., Site response in Tecoman, Colima, Mexico-I: Comparison of results from different instruments and analysis techniques. Soil Dyn. Earthquake Eng., 2010, 30, 711-716

[16] Bonnefoy-Claudet, S., Cotton, F. and Bard, P.Y., The nature of seismic noise wavefield and its implications for site effects studies. A literature reviews. Earth. Sci. Rev., 2006a, 79, 205-227

[17] Lachet, C. and Bard, P.Y., Numerical and theoretical investigations on the possibilities and limitations of the "Nakamura's" technique. J. Phys. Earth, 1994, 42, 377-397

[18] Şengör, A.M.C., Tüysüz, O., Imren, C., et al., The North Anatolian Fault, A new look. Annual Review of Earth and Planetary Sciences, 2004, 33, 1-75

[19] Armijo, R., Pondard, N., Meyer, B., Uçarkus, G., Mercier de Lépinay, B., Malavieille, J., Dominguez, S., Gustcher, M., Schmidt, S., Beck, C., Çağatay, N., Çakır, Z., İmren, C., Eris, K., Natalin, B., Özalaybey, S., Tolun, L., Lefévre, I., Seeber, L., Gasperini, L., Rangin, C., Emre, Ö. and Sarıkavak, K., Submarine fault scarps in the Sea of Marmara pull-apart (North Anatolian Fault): Implications for seismic hazard in İstanbul. Geochem. Geophy. Geosyst., 2005, 6, 6, Q06009, doi:10.1029/2004GC000896 
[20] Özgül, N., Üner, K., Bilgin, İ., Korkmaz, R., Özcan, İ., Akmeşe, İ., Yıldız, Z., Yıldırım, Ü., Akdağ, Ö., Tekin, M., İstanbul ì Alanının Genel Jeoloji Özellikleri. İstanbul Büyükşehir Belediyesi Deprem ve Zemin İnceleme Müdürlüğü, Türkiye, 2005

[21] ABEM., Instruction manual, Terrameter SAS4000/SAS1000, 2010

[22] RES2DINV, Rapid 2D resistivity \& IP inversion using the leastsquares method, Geoelectric Imaging 2D \& 3D, Geotomo software (http://www.Geoelectric.com)

[23] Park, C.B., Miller, R.D., Xia, J., Multi-channel Analysis of Surface Waves. Geophysics, 1999, 64, 800-808

[24] McMechan, G.A., Yedlin, M.J., Analysis of dispersive waves by wave field transformation. Geophysics, 1981, 46, 869-874

[25] Xia, J., Miller, R.D., Park, C.B., Tian, G., Inversion of high frequency surface waves with fundamental and higher modes. J. Applied Geophysics, 2003, 52, 1, 45-57

[26] Nogoshi, M. and Igarashi T., On the propagation characteristics of microtremor. J. Seism. Soc. Jpn., 1970, 23, 264-280.

[27] Duval, A.M., Mèneroud, J.P., Vidal, S. and Bard, P.Y., Usefulness of microtremor measurements for site effect studies. In: Proc. 10th Europ. Conf. Earthq. Eng., Vienna, 1994, 1, 521-527

[28] Duval, A.M., Bard, P.Y., Méneroud, J.P. and Vidal, S., Mapping site effect with microtremors. In: Proc. 5th Int.Conf. on Seismic Zonation, Nice, France, 1995, 1522-1529

[29] Konno, K. and Ohmachi, T., Ground motion characteristics estimated from spectral ratio between horizontal and vertical components of microtremor. Bull. Seism. Soc. Am., 1998, 88, 228-241

[30] Fäh, D., Kind, F. and Giardini, D., A theoretical investigation of average $\mathrm{H} / \mathrm{V}$ ratios. Geoph. J. Int., 2001, 145, 535-549

[31] Lermo, J. and Chavez-Garcia, F.J., Site effects evaluation using spectral ratios with only one station. Bull. Seism. Soc. Am., 1993, 83, 1574-1594

[32] Gitterman, Y., Zaslavsky, Y., Shapira, A. and Shtivleman, V., Empirical site response evaluations: case studies in Israel. Soil Dyn. Earthq. Eng., 1996, 15, 447-463
[33] Bard, P.Y., Effects of surface geology on ground motion: recent results and remaining issues. In: Proc. $10^{\text {th }}$ Europ. Conf. Earthq. Eng., Vienna, 1994, 1, 305-323

[34] Bard, P.Y., Microtremor measurement: a tool for site effect estimation? Inkura K., Kudo K., Okada H., Sasatani T. (eds), The Effects of surface Geology on Seismic Motion, Balkema, Rotterdam, 1998, 1251-1279

[35] Kudo, K., Practical estimates of site response, state of the art report. In: Proc. 5th Int. Conf. on Seismic Zonation, Nice, France, 1995, 3, 1878-1907

[36] Duval, A.M., Vidal, S., Meneroud, J.P., Singer, A., DeSantis, F., Ramos, C., Romero, G., Rodriguez, R., Pernia, A., Reyes, N. and Griman, C., Site effect determination with Microtremors. Pure Appl. Geophys., 158, Caracas, Venezuela, 2001, 2513-2523

[37] GEOPSY., 2016. http://www.geopsy.org/

[38] IMM., Geological-Geotechnical Study Report According to the Construction Plans as a Result of Settlement Purposed Microzonation Works, T.R. İstanbul Metropolitan Municipality Department of Earthquake Risk Management and Urban Development Directorate of Earthquake and Ground Analysis, Final Report (Summary Report), Oyo International Corporation, 2007

[39] Aşcı, M., Doğan, B., Yas, T. and Çaka, D., Determination of the deep fault geometry along the southern branch of the North Anatolian Fault System by using resistivity and magnetic methods. Journal of Asian Earth Sciences, 2016, 125, 1, 117-137

[40] Knödel, K., Krummel, H., Lange, G., Geophysik. Handbuch zur Erkundung des Untergrunds von Deponien und Altlasten. Bundesanstalt für Geowissenschaften und Rohstoffe, vol. 3. Springer, Berlin, 1997, 1063

[41] Lowrie W. Fundamental of geophysics, Cambridge University Press, Switzerland, 1997, 254

[42] Aning, A.A., Tucholka, P. and Danuor, S.K., 2D Electrical Resistivity Tomography (ERT) Survey using the Multi-Electrode Gradient Array at the Bosumtwi Impact Crater, Ghana. Journal of Environment and Earth Science, 2013, Vol. 3, 5 